\title{
THE DEMAND FOR MEDICAL MALE CIRCUMCISION
}

\author{
JoBiBa CHINKHUMBA, UnIVERSITY OF MALAWI \\ SUSAN GODLONTON, UNIVERSITY OF MichIGAN \\ REBECCA THORNTON, ${ }^{1}$ UnIVERSITY OF MichIGAN
}

\begin{abstract}
This paper measures the demand for adult medical male circumcision using an experiment that randomly offered varying-priced subsidies and comprehensive information to 1,600 uncircumcised men in urban Malawi. We find low demand for male circumcision: only three percent are circumcised over a three month period. Despite the low overall level of take-up, both price and information are significant determinants of circumcision. Still, the main barriers to male circumcision - cultural norms and fear of pain - are not affected by prices or information. Significant demand generation efforts are needed for this HIV prevention strategy to be effective.
\end{abstract}

\footnotetext{
${ }^{1}$ Corresponding author: Department of Economics, University of Michigan, 213 Lorch Hall, 611 Tappan St. Ann Arbor MI, 481091220, USA; rebeccal@umich.edu; Funding for this study was provided by 3ie, and the Rackham faculty grant at the University of Michigan. The authors gratefully acknowledge use of the services and facilities of the Population Studies Center at the University of Michigan, funded by NICHD Center Grant R24 HD041028. We are grateful for the hard work and cooperation of BLM and especially Brendan Hayes as well as the data and DMPTT model from UNAIDS and the authors in Njeuhmeli et al. (2011). We acknowledge the extensive contributions of the field team including Eirin Forsund, Victor Kanje, Ernest Mlenga, Ephraim Mwaipopo, Christopher Nyirenda, Justin Schon, Kelvin Balakasi, Thandizo Shaba, Hector Chilimani, Ronald Manjolo, Matthews Mfune, and Collins Zamawe. We thank Dave Knapp for assistance with coding. We also thank the Development Ideational Change Project at the University of Michigan Population Studies Center as well as helpful contributions from Taryn Dinkelman, David Lam, Emily Oster, Nancy Padian, Jeff Smith, and two anonymous referees.
} 


\section{Introduction}

Recently, three randomized control trials have found that medical male circumcision reduces the likelihood of contracting HIV for men by up to 60 percent (Auvert, et al., 2005; Bailey et al., 2007; Gray et al., 2007). ${ }^{2}$ Given these findings, in 2007 the WHO and UNAIDS officially recommended voluntary medical male circumcision (VMMC) as an important HIV prevention strategy and called for scale-up in 14 high priority countries in Eastern and Southern Africa (WHO, 2007). Since then, there has been global mobilization for scaling up male circumcision in high HIV prevalence areas.

Results from simulations and meta-studies support the claim that male circumcision is one of the most cost-effective HIV prevention interventions. The most recent simulations suggest that scaling up medical male circumcision to 80 percent coverage in priority countries could avert approximately 22 percent HIV infections through 2025, resulting in a net savings of US\$16.51 billion (Njeuhmeli et al., 2011). ${ }^{3}$ However, to reach this target, more than 20 million 15 to 49 year old men must be circumcised, by 2015. Given this ambitious goal, it is important to understand the demand for adult medical male circumcision in Africa.

Prior acceptability studies have been limited to focus groups or surveys asking uncircumcised men whether they would be willing to get circumcised. Aggregate statistics of the number of men circumcised in a particular area also do not provide sufficient information to estimate demand because it is unknown how many men chose not to get circumcised. Still, media reports imply very high demand for medical male circumcision and journalists report long lines at clinics throughout Eastern and Southern Africa (Zimdiaspora, 2010; PlusNews, 2010; Thom, 2009).

\footnotetext{
${ }^{2}$ The effectiveness of male circumcision ranged across the three countries: South Africa at 60 percent, Kenya at 53 percent, and 55 percent in Uganda. In Uganda, 45 percent of eligible men agreed to participate. After the close of the study, 80 percent of men in the control group who were offered circumcision agreed to be circumcised (CHIPTS, 2008). Among a minority of researchers there is still a debate regarding the the link between male circumcision and HIV (see for example, Dowsett and Couch (2007) or Mills and Siegfried (2006)).

${ }^{3}$ See also UNAIDS/WHO/SACEMA (2009), WHO (2011), Hankins et al. (2011), Nagelkerke et al.(2007), White et al. (2008), Williams et al. (2006).
} 
This study is the first to our knowledge that quantifies the actual demand for voluntary adult medical male circumcision. In addition to measuring the level of the demand, we also estimate how it varies by randomly set prices and randomly shared information about the benefits of male circumcision against HIV infection. Price and information interventions are most commonly used to increase the take-up of health goods in developing countries and it has been suggested that these also would be important for the adoption of male circumcision.

The data for this study were collected in urban Malawi in collaboration with a private clinic providing voluntary adult medical male circumcisions as an integrated part of their regular reproductive health services. A baseline survey was conducted among a representative sample of approximately 1,600 uncircumcised adult men in the catchment area of the clinic. At the end of the baseline survey, each respondent received a voucher for a subsidized male circumcision at the local partner clinic with the amounts of the vouchers randomly assigned. In addition, approximately half of the men were told detailed information about male circumcision and HIV transmission. Data from the clinic were collected and follow-up interviews conducted one year later indicating whether men had been circumcised.

We find low demand for medical male circumcision: three percent of the men interviewed at baseline were recorded as being circumcised at the clinic. Despite the low take-up, the subsidy had a significant impact on the demand for medical male circumcision: decreasing the price from 6 dollars to free increased the probability of circumcision by 3.1 percentage points. We also find a significant difference in take-up among those who were given detailed information about circumcision and HIV: those given additional information increased their likelihood of take-up by almost two percentage points. There was no significant interaction between information and price.

Due to the small sample size of those who were circumcised, our ability to estimate which types of men select into the surgery is limited. However, we do find some suggestive evidence. Not surprisingly, those who reported as willing to be circumcised at baseline were the most likely to get a medical circumcision. Men living closer to the 
clinic or who had heard that others had been circumcised at the clinic were more likely to get circumcised. Ex-ante risk may also predict selection into male circumcision: men who used a condom that last time they had sex and those who had fewer sex acts in the past month are more likely to get circumcised in our data. If men who are least at risk of HIV are most likely to adopt male circumcision, universal male circumcision roll-out campaigns will be less cost-effective than estimates suggest. However, we caution generalizing these results given the small sample of men who take-up circumcision.

While price and information were important barriers for some men, simply providing free medical circumcisions and comprehensive information was not enough to motivate most to get circumcised. At baseline, the most common reasons men cited were cultural or religious norms or the fear of pain from the surgery. While the information and price of circumcision significantly affected attitudes towards future circumcisions along some dimensions, there were no impacts on views about norms or pain.

There are several important limitations to our findings. First, the study was conducted during the initial phases of male circumcision scale-up in Malawi. It may be that future demand increases with more government support, information campaigns, and with increased male circumcision acceptability within the population. Second, our analyses measuring the determinants of take-up are identified off of a small sample and the results should be interpreted with this in mind. Third, our results do not speak to the effect of negative prices on the demand for male circumcision, which may be one way that would stimulate demand, especially given the physical and psychological costs of the surgery.

Still, our results have significant policy implications and make important new contributions to the literature. First, the demand for medical male circumcision may be much lower than previous acceptability studies or media reports suggest. Second, simply providing free medical male circumcisions and information about male circumcision and HIV transmission was not enough to generate sufficiently high demand that would induce significant population level benefits. Moreover, these interventions had no impact on changing attitudes about cultural and religious norms about male circumcision or the fear of pain from the surgery. The implication of our results is that reaching the goal of 
circumcising 80 percent of adult men by 2015 may be much more difficult than merely increasing the supply of free circumcisions.

The paper proceeds as follows: Section 2 presents background information on male circumcision and what is known about the determinants and barriers to take-up. Section 3 presents the data and experiment. Section 4 presents the results on male circumcision take-up. Section 5 outlines the empirical strategy to identify the effects of price and information on take-up. Results are presented in Section 6. Section 7 discusses other possible barriers to take-up and Section 8 concludes.

\section{Background}

\section{A. Traditional Male Circumcision in Malawi}

It is currently estimated that approximately 11 percent of adults are infected with HIV in Malawi, giving the country the $9^{\text {th }}$ highest infection rate in the world (UNAIDS, 2010). Malawi was named as a high priority country for the scale-up of medical male circumcision not only because of its high HIV prevalence, but also because the majority of men (81 percent) are not circumcised (MDHS, 2010). As in other African countries, the practice of male circumcision is deeply cultural and is typically conducted as part of an initiation to adulthood among adolescent boys (Stannus and Davey, 1913). In Malawi, 85 percent of those belonging to the Yao tribe are circumcised, typically during initiation ceremonies. In other tribes, male circumcision is not as prevalent with 21 percent of the Mang'anja, 32 percent of the Nyanja, and 30 percent of the Lomwe circumcised (MDHS, 2010). Other tribes such as the Chewa, Tumbuka, Tonga, Sena, Ngoni, or the Nkhonde have much lower rates of circumcision. The rate of male circumcision is also highly correlated with religion; 94 percent of Muslims are circumcised.

\section{B. Quantifying the Demand for Medical Male Circumcision}


To reach the target of 80 percent male circumcision coverage, Malawi would need to circumcise over 2 million men (WHO, 2011). However, quantifying how many of those men will be actually willing to become circumcised is difficult. Anecdotally, media reports from several countries in Eastern and Southern Africa suggest a very high demand for medical male circumcision describing men lining up at clinics for a circumcision (Zimdiaspora, 2010; PlusNews, 2010; Thom, 2009). In Malawi, focus group discussions conducted in 2003 among 159 men and 159 women ages 16-80 years suggested that "many men and women would welcome male circumcision services if they were safe, affordable and confidential” (Ngalande et al., 2006). It is difficult, however, to rigorously quantify the true demand for male circumcision surgery from these reports.

One approach to quantifying the demand for medical male circumcision is to ask uncircumcised men if they would be willing to get circumcised. A meta-analysis of 13 sub-Saharan African countries found that the median willingness to get circumcised among uncircumcised men was 65 percent, ranging from 29 to 87 percent across countries (Westercamp and Bailey, 2007). In Malawi, approximately 37 percent reported that they would be willing to get circumcised in 2010 (Bengo et al., 2010). ${ }^{4}$ However, it is difficult to infer true behavior from hypothetical answers about the willingness to get circumcised (Westercamp and Bailey, 2007; Muula, 2007).

Another approach to quantifying the demand for male circumcision is to simply count the number of medical male circumcisions conducted within a country or region. By the end of 2010, just over 555,000 medical circumcisions were performed for HIV prevention in the 14 priority countries, representing approximately only 2.7 percent of the target. $^{5}$ In Malawi, one estimate provided by the Ministry of Health reports that 3,119 medical male circumcisions were conducted in facilities across the country between 2008 and 2010 (WHO, 2011). ${ }^{6}$ However, many of these circumcisions may be substituting for

\footnotetext{
${ }^{4}$ Households were sampled across selected districts based on the expected prevalence of male circumcision using the results of 2004 Malawi Demographic and Health Survey (MDHS 2004). The survey included men older than 18 . Initially, 81 percent of men reported being opposed to circumcision. After being told about the benefits of male circumcision, this percentage declined to 63 percent.

${ }^{5}$ Half of these were conducted in Kenya, achieving 27 percent of their national goal (WHO, 2011).

${ }^{6}$ Another estimate from a Ministry of Health official in early 2012 suggested that "more than 5,000 men have so far been circumcised” (Irin Plus News, 2012).
} 
traditional circumcisions. Records of the circumcisions conducted at health facilities in 2010 found that only 14.8 percent were adults; the remaining constituted infants, children and adolescents (Bengo et al., 2010).

These statistics may suggest fairly low demand for male circumcision; alternatively they may reflect limited supply or access. Moreover, facility-based reports of the number of men circumcised do not provide sufficient information to estimate how many men chose not to get circumcised; those statistics are missing the denominator that is needed to estimate demand. ${ }^{7}$

\section{Determinants of and Barriers to Take-up}

Previous studies have explored possible barriers to take-up of medical male circumcision; the majority, however, as discussed above, use hypothetical acceptance as a measure of demand rather than observing actual circumcisions. In addition, most are unable to determine causal relationships due to omitted variables that may be correlated to both demand and other factors.

Perceptions of the costs of a medical male circumcision have been reported as barriers to take-up. These include the perception of a long healing period, perceived pain associated with the surgery, lost wages, or the cost of the circumcision procedure itself (Westercamp et al., 2012; Herman-Roloff et al., 2011; Lukobo and Bailey, 2007). ${ }^{8}$

The belief or knowledge that circumcision is protective against HIV may also be an important determinant of hypothetical demand (Westercamp et al., 2012; Bengo et al., 2010; Albert et al., 2011). In a paper most similar to ours, Godlonton et al. (2013) measure actual male circumcision take-up among men living in rural Malawi. In that

\footnotetext{
${ }^{7}$ One pilot program began offering free medical male circumcisions in 2010. A three month campaign increased circumcisions from approximately five men per month in the months preceding the pilot, to four men per week during the campaign. In total, 99 circumcisions were conducted (Jung, 2012). To reach this level of take-up, the program had to conduct intensive community sensitization at local markets including songs, question and answer sessions, short dramas, as well as brochures about medical male circumcision. Determining the actual fraction of men who demanded the service in this context is not possible as the total number of men reached through these campaigns, although likely very high, is not provided.

${ }^{8}$ Using estimates of willingness to pay from actual circumcision data in Kenya, Bailey, Muga et al. (2002) found that circumcisions at one clinic "increased significantly" when the price was lowered from 250KSH to $100 \mathrm{KSH}$. However, because the price was not randomly assigned, it is not possible to attribute the increase in circumcisions explicitly to the price change. In the Malawi Circumcision Situational Analysis, uncircumcised men were asked how much they would hypothetically be willing to pay for a circumcision. About two thirds indicated they were willing to pay up to MK1,000 (US\$7) with approximately a fourth, preferring not to pay anything (Bengo et al., 2010).
} 
study, comprehensive information about male circumcision and risk of HIV infection was randomly allocated across villages. After one year, only seven men had gotten circumcised and there was no significant impact of the comprehensive information. One of the possible reasons for low take-up in that study is that the villages were quite remote and the distance to the closest clinic may have been restrictively far. In contrast, this paper studies an urban population living in close proximity to a well-known clinic.

Ex-ante risk preferences or risk type may also affect the demand for male circumcision. Men who face a high risk of HIV infection have the largest benefit of the surgery. Alternatively, if men who practice safe sex have a preference for safe behavior, they may have the highest demand for circumcision. ${ }^{9}$

With the exception of Godlonton et al. (2013), there are no studies to our knowledge that quantify the demand for, willingness to pay for, or selection into actual medical male circumcision. Our study fills this gap by first, providing an estimate of the demand for male circumcision by measuring the percent of eligible men in the study who obtain an actual circumcision; second, estimating the actual willingness to pay by comparing takeup between those randomly allocated various prices of circumcision; and third, estimating the causal effect of providing information about male circumcision and HIV on take-up.

\section{Data and Experiment}

\section{A. Partner Clinic}

While officially, government hospitals and clinics in Malawi offer medical male circumcisions free of charge, in reality, elective circumcisions are considered low-priority

\footnotetext{
${ }^{9}$ Another possibility is that the decision to have a circumcision could also be influenced by a man's desire to signal lower risk of HIV infection. While not observable prior to sexual intimacy, circumcision could signal that a man has lower risk of HIV infection. This could lead to riskier sex, or potentially safer sex, if a circumcised man can better negotiate for a partner who herself has lower risk. Risk compensation may be an important consideration in predictions of the marginal benefit of circumcision. If high risk men respond to the surgery with an increase in risky behavior then the marginal benefit from circumcision might be lowest for the risky types (Cassell, 2006; Kalichman et al., 2007). Most empirical evidence, however, suggests that risk compensation after circumcision is limited (Godlonton et al., 2013; Wilson et al., 2013; Mattson et al., 2008).
} 
compared to other surgical procedures and are not readily available. ${ }^{10}$ To conduct our study, we partnered with a private provider that had begun offering circumcisions in 2010, becoming a leader in the private provision of medical male circumcision in Malawi. ${ }^{11}$ The clinic, which primarily offers family planning and basic health services, has over 31 branches covering the majority of the population in urban and peri-urban areas across the country. Importantly, the clinic follows a model in which patients are charged small fees for health services or products. In 2010, several branches of the partner clinic began offering circumcisions for a price of 950 Kwacha (approx. \$6.75). ${ }^{12}$

The circumcision procedure itself is an outpatient surgery that begins with a local anesthetic injection. Often clients report this to be the most painful part of the procedure. Dissolvable stitches are used and men are advised to return to the clinic for a follow-up visit; clients are given painkillers to take for several days after the surgery. There is a recommended six-week period of sexual abstinence and most men resume work within two to three days after the surgery. Those who do sedentary jobs can often resume work immediately after the procedure.

\section{B. Survey Data}

The survey data were collected within the catchment area of one partner clinic branch in the capital city of Lilongwe. The catchment area constitutes 29 enumeration areas as defined by the Malawian National Statistics Office. Each enumeration area was subdivided into a total of 114 neighborhood blocks which were demarcated using roads and rivers as natural dividing lines. Blocks were randomly selected into the study, stratified by enumeration area. On average there were 4 blocks per enumeration area.

\footnotetext{
${ }^{10}$ More commonly, government and CHAM facilities serving populations that traditionally circumcise offer medical male circumcisions services during certain times of the year when most traditional initiation ceremonies take place. In a 2010 assessment of service providers, less than 30 percent of community hospitals had the capacity to begin offering medical male circumcision (Bengo et al., 2010). In addition, a separate analysis of Malawi's medical staff found a 62 percent vacancy rate across the country (Lawson et al., 2008) and according to Mary Shawa, the previous Principal Secretary for HIV/AIDS and Nutrition in the Office of the President and Cabinet, "only 4 percent of the country's medical staff have been trained to carry out the surgical procedure” (Irin Plus News, 2012).

${ }^{11}$ Not until October 2011 did the government adopt medical male circumcision as part of their national HIV prevention strategy and thus access to services are limited as policy leaders have called for caution in scaling up (Namangale, 2007; Tenthani, 2010)

12 This fee covered all surgery expenses, pain medications, follow-up review, and the treatment of any complications. The clinical protocol for an adult male circumcision at the partner clinic includes group education, individual counseling and STI screening, referral for voluntary testing HIV testing and post-test counseling.
} 
Within each selected block, a household census was conducted in which men who were eligible for the study were identified. Eligibility was defined as any man - regardless of circumcision status - who was a permanent resident in the household and between the ages of 18 and 35 years. In households with more than one eligible man, one man was randomly selected as the target respondent. ${ }^{13}$

After the selection of an eligible respondent and obtaining informed consent, the baseline survey would commence, first with questions to determine the respondent's circumcision status. The full survey was only administered to uncircumcised men. In total 1,634 uncircumcised men completed baseline surveys. Follow-up surveys were conducted in 2011, approximately one year after the baseline in which 77 percent of the men who were interviewed at baseline were re-interviewed. ${ }^{14}$ We use two samples in our analysis, the full sample of 1634 men interviewed at the baseline and the follow-up sample of 1,252 men who were interviewed at both the baseline and the follow-up.

\section{Randomization}

Immediately after the baseline survey, each respondent was given a voucher for a subsidized circumcision at the partner clinic branch, valid for approximately three months. Vouchers contained a voucher ID that could be linked to each respondent, the name of the respondent, as well as the type of photo ID which would be used to redeem the voucher. ${ }^{15}$ The value of the vouchers ranged from a full subsidy in which the circumcision was free, to a small subsidy in which the respondent had a 50MKW discount (\$0.33) and had to pay 900MKW (\$6). ${ }^{16}$ Vouchers were randomized at the

\footnotetext{
${ }^{13}$ Data from the Demographic and Health Survey of Malawi finds that 23 percent of men living in urban areas in the Central Region (where Lilongwe is located) were circumcised. This is slightly higher than the 19 percent male circumcision prevalence rate across the entire country.

${ }^{14}$ The attrition rate is relatively higher than other panel studies in rural Africa mainly due to the high mobility of men living in an urban area (Anglewicz et al., 2009).

${ }^{15}$ Respondents were asked in the first section of the baseline questionnaire what type of photo ID they had (e.g., voter ID, driving license, school ID). The ID type was written on the voucher to prevent voucher transfers. 14.5 percent of respondents had no photo ID. ${ }^{16}$ Note that every man who participated in the survey received a voucher that subsidized the price of a circumcision. This was done to insure a credible link between the respondent and clinic attendance (there would be little incentive to bring a voucher worth nothing to the clinic). The distribution of the vouchers included 24.17 percent full subsidy; 25.48 percent 50MKW price; 13.55 percent 100MKW price; 13.18 percent 200 MKW price; 12.93 percent 400 MKW price; and 10.68 percent 900 MKW price.
} 
individual level. ${ }^{17}$ Data from the Integrated Household Survey (IHS 2004/05) reveal that average daily wages in Lilongwe for men were $127 \mathrm{MKW}$ per day with a median of $100 \mathrm{MKW}$ per day. Thus for some respondents, the cost of the surgery was significant and the vouchers would be viewed as a significant discount. ${ }^{18}$

Half of the respondents were also randomly assigned - by day of the initial household census - to receive comprehensive information about male circumcision and HIV. Men receiving comprehensive information were informed that circumcision is partially protective against HIV transmission. Interviewers explained the results from the three randomized control trials in Uganda, South Africa and Kenya. Information was also provided about some of the medical reasons why circumcision is partially protective. Those who did not receive the comprehensive information were simply told about the partner clinic's services and that male circumcision was available there. On average, 11 additional minutes were spent administering the baseline survey among those assigned to the information group (not shown).

\section{Sample}

Table 1, Column 1 presents the summary statistics for the full sample of the 1634 men interviewed at baseline. ${ }^{19}$ The sample consists of men who are on average almost 27 years old and relatively well educated, completing eleven years of school. Individuals spend approximately $\$ 142(21,325 \mathrm{MK})$ per month on various expenses (median of \$99). ${ }^{20}$ Just more than 17 percent of the respondents are from a circumcising tribe, defined as a tribe with over 20 percent circumcised men in the Demographic and Health

\footnotetext{
${ }^{17}$ Vouchers were placed in sealed envelopes and stapled to the back of the questionnaire; questionnaires were given to enumerators in random order, shuffled by the authors. There is no significant difference in the distribution of vouchers allocated as compared to what was intended (not shown).

${ }^{18}$ Other experiments in Malawi have found large responses to small incentive amounts. One study offered cash incentives to learn their HIV results after testing found that 10 Kwacha increased the likelihood of traveling for HIV results by almost 20 percentage points (Thornton, 2008). Another study randomly offered 30 Kwacha to individuals for one day's work found that 80 percent of individuals showed up for work (Goldberg, 2012).

${ }^{19}$ Our sample is generally similar to other studies conducted in urban Malawi. For example, urban men living in the Central region in the MDHS (2010) had on average 7.7 years of education, 25 percent had used a condom at last sex, and 55.6 percent had ever been tested for HIV. The ethnic composition of respondents is not representative of the study area due to the fact that only uncircumcised men were eligible for the study; approximately one third of the men are Chewa (34.6 percent), 24.7 percent Ngoni, 13.5 percent Lomwe, 12.8 percent Tumbuka, and the remaining 15 percent include Nkhonde, Nyanja, Tonga, Yao and others (not shown).

${ }^{20}$ Expenditures categories were: Clothes, fabric, or shoes, Medical expenses at a clinic, doctor, pharmacy, or traditional doctor, Food: maize, meat, vegetables, eating out, transportation costs, and cell phone minutes. We report pre-devaluation prices
} 
Survey (MDHS, 2010). ${ }^{21}$ Most men in the sample have ever had sex (87.5 percent; not shown), and have had approximately 4.2 sexual acts in the past month. Just less than half of the men (46.1 percent) report abstaining from sex in the past month with almost 6 percent reporting having multiple partners. Of those who had sex in the last month 39.5 percent report using a condom the last time they had sex. On average, 21.7 percent of the sample report they have a high likelihood of being currently HIV-positive. Just under half (48 percent) have ever had an HIV test.

We asked a number of questions to elicit perceptions about male circumcision. When asked about their beliefs about male circumcision and HIV, 49 percent had the correct prior belief that circumcised men were less likely to contract HIV. ${ }^{22}$ Almost half of the men (49 percent) reported that they were willing to be circumcised. This is slightly lower than the median acceptability rate of 65 percent from circumcision acceptability studies across Sub-Saharan Africa (Westercamp and Bailey, 2007), but higher than the Malawi Situational Analysis from Lilongwe where 37 percent reported the willingness to get circumcised (Bengo et al., 2010). On average, men lived approximately one kilometer away from the partner clinic and 19 percent had ever heard of someone getting circumcised there.

If men reported they were unwilling to get circumcised, interviewers inquired about the reason they were unwilling (Figure 1). ${ }^{23}$ The two most common reasons given were due to culture or religion (45.1 percent) or fear of pain (32.9 percent). Other important reasons included feeling they were too old (18.3 percent) or “just not wanting to" (7 percent). Fewer, 2.3 percent, reported not having enough information or seeing no benefit and ever fewer reported feeling they were not at risk, being too busy, facing family objections, that the surgery was too expensive, or that they were too busy.

\section{Take-up of Voluntary Medical Male Circumcision}

\footnotetext{
${ }^{21}$ This includes the Yao, Mang'anja, Nyanja, and Lomwe.

${ }^{22}$ To elicit these beliefs, respondents were asked about the perceived transmission rate for circumcised men and for uncircumcised men. Perceived HIV transmission probabilities are measured by the following: i) "If 100 circumcised men each slept with a woman who is HIV positive last night, how many of them do you think would get HIV?"; and ii) "If 100 uncircumcised men each slept with a woman who is HIV positive last night, how many of them do you think would get HIV?"

${ }^{23}$ Men’s responses were coded after being allowed to respond to an open ended question.
} 
To measure the demand for medical male circumcision, we use two sources of data: clinic data and follow-up survey data. The clinic provided data on each voucher redeemed for an adult medical male circumcision up to six months following the start of the baseline survey. These data were recorded by intake nurses at the time that a respondent presented his voucher. In addition to clinic data, the follow-up surveys asked the respondent if he had received a circumcision in the past year.

Table 2 presents the take-up of male circumcision from the clinic and survey data. Out of the 1,634 men who were interviewed at baseline, the clinic reported that 43 vouchers were redeemed, a take-up rate of 2.63 percent (Panel A). Restricting the sample to the 1,252 men who were also interviewed at the follow-up, the take-up rate was 3.3 percent, as measured by redeemed vouchers (Panel B). Of the 41 men who had clinic records and who were interviewed at the follow-up, the majority, 35, reported having a circumcision at the clinic during the validity period. The remaining 6 reported not being circumcised (Panel C).

The follow-up survey provides additional information about the demand for male circumcision. First, 26 percent report that they had some interaction with the partner clinic; examples of these interactions are undergoing circumcision surgery, being counseled, making a visit or a phone call to the clinic to inquire about circumcision (Table 2, Panel B). In addition to the vouchers redeemed at the clinic, an additional 70 men report having received a circumcision. Of these, 25 reported getting circumcised at either a non-partner clinic or traditionally, 9 reported getting circumcised at the partner clinic but after the expiration date of the vouchers, and 36 reported getting a circumcision at the partner clinic while the vouchers were still valid. Men may report getting circumcised when in reality they did not. This may be the case especially for the 36 men who reported receiving a circumcision at the partner clinic during the validity period but there was no voucher collected. On the other hand, vouchers may have been misplaced or records not accurately kept during intake or at the time of the surgery.

In total, the rate of take-up was between 3 percent - using clinic data only - and 8.9 percent - from either clinic or survey data. 


\section{Determinants of Take-up: Empirical Strategy}

Undergoing a medical male circumcision is a big decision. To some, the low circumcision take-up rate in our study may not be surprising given the financial, social, and psychological costs associated with the surgery. On the other hand, some men did get circumcised; understanding the determinants of take-up may provide insights that could benefit medical male circumcision scale-up efforts. Because price and comprehensive information were randomly allocated at the baseline, we can measure the causal effect of these factors. We also examine how various personal characteristics are correlated with take-up. Importantly, because of the low overall rate of take-up, the results in this section should be interpreted as suggestive, as they may not be generalizable to other settings or in cases in which there is higher demand.

To estimate the determinants of the take-up of male circumcision, our preferred specification is:

(1) $Y_{i j}=\alpha+\beta_{1}$ Free $_{i j}+\beta_{2} 50_{i j}+\beta_{3} 100_{i j}+\beta_{4} 200_{i j}+\beta_{5} 500_{i j}+\beta_{6}$ Info $_{i j}+\gamma^{\prime} X+\varepsilon_{i j}$

We are interested in three different outcome measures, $Y_{i j}$ for individual, $i$, living in neighborhood block, $j$ : (i) circumcised based on clinic data, (ii) circumcised based on clinic data and self-reported circumcisions at the partner clinic within the voucher validity period, and (iii) having had any interaction with the partner clinic.

To estimate the impact of price, we use a flexible specification with indicators for each price point. Free indicates whether an individual was offered a free circumcision, and 50, 100, 200, and 500 are indicators of the amounts needed to pay for male circumcision at the partner clinic (900MKW is the omitted category). ${ }^{24}$ Info is an indicator of whether the respondent was assigned to receive the comprehensive information about circumcision. The vector of baseline variables, $X$, include: age, age squared, logged total expenditures,

${ }^{24}$ The coefficient on log price on circumcision take-up from the clinical records is -0.0031 (p-value $=0.000$; no controls). 
years of schooling, indicators of belonging to a circumcising tribe, being willing to be circumcised, believing his risk of having HIV was high, having ever had an HIV test, the interaction of belief of high risk and having an HIV test, having heard of anyone who was circumcised at the partner clinic, correctly believed that circumcision was associated with lower risk of HIV, distance to the clinic, number of sex acts in the last month, and indicators for whether the respondent used a condom at last sex, abstinence in the last month, and multiple concurrent partnerships. For covariates with missing values, we impute the median and include a dummy indicating whether or not the covariate is missing.

We estimate (1) above linearly, although probit estimates do not yield qualitatively different results. Robust standard errors are clustered by block (the primary sampling unit) and by day (the unit of randomization for the information treatment).

Because the voucher amount and information were randomly allocated to respondents, the error term is uncorrelated with $\beta_{1}$ through $\beta_{6}$ allowing us to measure the causal effects of price and comprehensive information on the demand for circumcision. If the subsidy had not been randomized, the price of circumcision may have been correlated to endogenous price changes, such as underlying community demand for male circumcision or government pressure to receive a circumcision. Similarly, if information had not been randomly assigned, the knowledge about male circumcision and HIV risk would likely be correlated with other factors such as risk preferences, education, or underlying propensity to get a circumcision, biasing the estimates of the effect of information.

The main assumption allowing for estimating the causal effects of price and information is that those facing different prices of male circumcision or learning comprehensive information are similar along observables and unobservables. Table 1, Column 2 presents, for each baseline variable, the p-value of an t-test of equality of the average values of the baseline characteristic across information treatment groups. Similarly, Column 3 presents the p-value of an F-test of joint equality of the mean values of each baseline characteristic at the randomly assigned prices. For almost all of the baseline characteristics we cannot reject equality suggesting that the respondents in the 
information groups and each price group are balanced on key observable characteristics. In total, we tested 50 baseline characteristics and 16 percent were statistically significant at the 10 percent level across the different assigned prices; 12 percent were statistically significant across the information treatment or control groups.

In addition, there are also no significant differences in follow-up survey completion across the information treatment groups or assigned prices; the p-value of the joint test of significance for having a complete follow-up survey is 0.705 or 0.964 , respectively (not shown). Attrition also does not differentially vary across price or information by baseline characteristics. To test this, we run separate regressions of being surveyed at the followup on each baseline characteristic, indicators for each information treatment (price), and interactions between the baseline variable and each information treatment indicator (price indicator). Column 4 and 5 present p-values from F-tests of joint equality of each of the interaction terms, across information treatment and prices, respectively.

\section{Determinants of Take-up: Results}

\section{A. Price}

Figure 2 illustrates the general relationship between price and the demand for male circumcision. It plots the take-up of male circumcision by price as measured by the clinic data. Take-up increases slightly from free to $50 \mathrm{MKW}$ and then declines monotonically thereafter with increasing price. No one was circumcised who had to pay the highest amount.

Table 3, Columns 1 through 4 presents regression estimates from equation 1 of the effects of price on actual circumcisions as measured by the clinical records. Those offered a free circumcision were 3.1 percentage points more likely to adopt than those offered a circumcision for $900 \mathrm{MKW}$. While the coefficient on being offered a price of $50 \mathrm{MKW}$ is higher at 4.1, these coefficients are not statistically significant from one another (p-value $=0.5296)$. Results are similar if we include controls (Column 2) or restrict the sample to only those who had follow-up surveys (Columns 3-4). 
If we expand our definition of circumcised to also include self-reported circumcisions at the partner clinic when the vouchers were valid, overall take-up is slightly higher, but the effects of price is roughly similar (Columns 5-6). There are also large and significant effects of price on having any interaction with the clinic (Columns 7-8). Those who received a higher subsidy were more likely to approach the clinic for more information or counseling, even if they did not choose to get circumcised at the end of that enquiry process. Those offered free circumcisions are 10.8 percentage points more likely to have interacted with the clinic than those offered a circumcision at 900MKW (Column 7). Again, including controls does not significantly change the magnitude or significance of the coefficients on price (Column 8). Note also that all of the results in Table 3 are robust to probit specifications (not shown).

There has been some discussion (as well as important ethical debates) about offering payments, for example a conditional cash transfer, to uncircumcised men to motivate them to get circumcised. Incentives may be one way to increase take-up by compensating men for costs associated with the surgery and recovery period. While our results on responses to prices are not informative for predicting responses to "negative prices" or financial incentives, future research offering compensation in either cash or kind may be an important next step.

\section{B. Information}

One possible reason for low circumcision take-up even when the procedure was free is that men did not know or understand the medical benefits of male circumcision. Recall that at baseline only 49 percent of men believed correctly that circumcision was protective against HIV. At the follow-up, men who received the comprehensive information treatment were significantly more likely to update their beliefs that circumcision decreased the risk of HIV infection. Men who received the information also 
reported significantly lower perceived transmission rates as measured by levels and relative risk between circumcised and uncircumcised men (Appendix Table A). ${ }^{25}$

Figure 3 graphs the impact of information on take-up. Receiving the comprehensive information about male circumcision significantly increased take-up; an effect between 1 and 1.8 percentage points (Table 4, Columns 1 through 4). We find no impact of information on take-up when we expand the definition of circumcised to include selfreported circumcisions at the partner clinic during the validity period, and we find no impact on having had any interaction with the partner clinic (Columns 5-8). Again, results are robust to probit specifications, although the size of the coefficient is smaller (not shown).

There is no significant impact of the information interacted with the price of the circumcision as illustrated by Figure 4, graphing circumcision take-up across price and information treatment group. However, we again caution that the small sample size of men who were circumcised limits our analyses.

Baseline beliefs about the relationship between male circumcision and HIV infection may be important to consider when examining the impact of knowledge on take-up. Wilson et al. (2013) found that men who had different beliefs about male circumcision and HIV responded differentially after getting a circumcision in terms of their sexual behavior. Similarly, it may be possible that only those receiving new information may respond in this study. While baseline beliefs are correlated with take-up, there is no additional effect of the comprehensive information (not shown).

\section{Other Determinants - Non-Randomized Results}

Table 5 presents how baseline characteristics are correlated with the take-up of male circumcision and having any interaction with the clinic. It is important to note that these variables were not randomized at baseline and thus do not represent causal estimates.

\footnotetext{
${ }^{25}$ This persistent effect from the information treatment is similar to that found in Godlonton et al. (2013) who randomized comprehensive information to a rural sample of men in Malawi and measured beliefs after one year. In contrast, beliefs about one's own HIV status has been found to only persist in the short run (Thornton, 2012).
} 
However, they can provide some insights into additional important factors for the demand for male circumcision.

One of the most important predictors of getting circumcised was openness to a circumcision defined as reporting willingness to be circumcised at the baseline. Those who reported being willing to circumcise at the baseline were between 2.6 and 3.1 percentage points more likely to receive a circumcision reported by the clinic, and almost 9 percentage points more likely to have had any interaction with the clinic.

There is no statistically significant effect of age on actual take-up, despite the large proportion of men who stated being "too old" was a reason to not get circumcised at baseline. This result should be viewed in the context of our sample, which only included men between age 18 and 35. Moreover, most men when stating they were "too old” were comparing themselves to the age that most Malawian boys are traditionally circumcised between 10 and 18 years old. ${ }^{26}$

While opportunity cost may be an important factor for the decision to get circumcised, data on income or employment is unavailable. Total household expenditure - included in the regressions - is one proxy for these other variables. Expenditures are not associated with circumcision take-up. This is somewhat contradictory to the finding that take-up was so responsive to price, suggesting credit constraints may be important. One explanation may be that measurement error in expenditures biases the coefficient towards zero. Another possibility is that the immediate small costs are more important than the actual ability to pay. We have some evidence of this. Men who were circumcised at the partner clinic were asked what their perceived opportunity cost was of receiving the surgery (ie., lost wages); on average they report 11,000MKW (approximately \$73; not shown). Expanding the sample to men who reported getting circumcised anywhere (i.e., including self-reports) they report a loss of $14,720 \mathrm{MKW}$ (\$98). In both cases, the median reported opportunity cost is $5000 \mathrm{MKW}$ (\$33). In contrast to these estimates, the voucher amounts are quite small.

\footnotetext{
${ }^{26}$ In data collected by Godlonton, Thornton and Munthali (2013), the age at circumcision is reported to range from $10\left(10^{\text {th }}\right.$ percentile $)$ to $18\left(90^{\text {th }}\right.$ percentile $)$.
} 
Distance to the clinic was negatively associated with take-up, but not with having any interaction with the clinic. Having heard of someone getting a circumcision at the clinic is also significantly associated with getting circumcised or having any interaction at the clinic.

Those who have ever had an HIV test are 8.3 percentage points more likely to have any interaction at the clinic, potentially indicating selection on risk preferences. However, there is no relationship between prior HIV testing and actual circumcisions. Neither exante beliefs of being infected nor these beliefs interacted with having a prior HIV test are significantly associated with getting a circumcision.

Lastly, we find that those who used a condom at last sex were significantly more likely to get circumcised - when the definition of circumcision is expanded to include selfreports. Our data are limited given the small take-up rate, but the extent of selection based on ex-ante risk would significantly affect the efficacy of male circumcision rollout and is important for future studies and programs to consider.

Why was the demand for medical male circumcision so low? We examine several possible explanations in the section below.

\section{Barriers to Take-up}

Recall that at the baseline, men who reported they were unwilling to get circumcised were asked why they were unwilling (Figure 1). The most common answers were cultural or religious reason, fear of pain, being too old, or just not wanting to get a circumcision. To gain insight into the low overall take-up, we examine how offering the vouchers and the comprehensive information affected attitudes towards male circumcision.

Men at the follow-up - who had not gotten circumcised - were again asked whether or not they would be willing to be circumcised. Approximately 75 percent reported they would be willing to get circumcised, despite the fact that they had not yet gone for the surgery. Those who were unwilling were asked why they were unwilling and those who reported being willing were asked why they had not yet received a circumcision. 
Although there are some differences in responses to information and price across these two groups of men, these differences are small and do not change the main results (not shown); we therefore pool these responses together.

Table 6 presents how information or price affects reported barriers to getting circumcised. There were no significant effects on reporting cultural or religious reasons, fear of pain, believing one is too old, or just simply not wanting to be circumcised (Columns 1-4). Importantly, these were the most commonly stated reasons for not getting circumcised at the baseline.

Prices had some effects on other reported barriers to circumcision. Those who were offered lower priced circumcisions were less likely to say expense was a barrier. They were also more likely to report being too busy. Information also had effects on barriers to male circumcision. Those receiving the comprehensive information were more likely to say they were not at risk, less likely to say they didn't have enough information, and more likely to report that a family member objected to the surgery. In total, there was a small significant increase in the total number of reasons/barriers given among those who were given the comprehensive information.

Importantly, there was no impact of either information or price on expressing any positivity towards circumcision - as coded from the open-ended questions - or on the expressed willingness to be circumcised.

These results help to understand the low take-up in this study and why the information and price interventions were unable to substantially increase it. Although many men state they are willing to get circumcised, in actuality, providing comprehensive information about the benefit and providing free clinical circumcisions are not enough to reduce the main barriers that constitute over half of the stated reasons against circumcision.

It is important also to note that there may also have been administrative or logistical barriers to take-up. Because the vouchers were only valid for 3 months, men may have demanded a circumcision at a different time or season when the opportunity costs were lower. Additionally, there were some reports that men were unable to schedule a time at the clinic when the clinician was available. This speaks to the importance of the need to 
promote both demand and ensure supply of male circumcision services. Among those men who made any contact with the clinic, they made an average of 2.25 calls to the clinic, 2.12 visits, and 1.9 attempts for surgery. Even among those who eventually got circumcised it took some effort; these men made 1.75 calls, 1.33 visits, and 2 surgery attempts.

\section{Conclusion}

This paper measures the demand for medical male circumcision and the response to price and information using a randomized trial. No prior study, to our knowledge, has measured the demand for male circumcision. Overall, the demand was relatively low ranging from 2.6 to 8.9 percent using clinic and self-reported data respectively. This is particularly low when compared to the target of 80 percent set for male circumcision rollout strategies.

Price was not the only barrier to receiving a male circumcision, but certainly was for some. In addition, information - while a significant factor - is not the main barrier to take-up. Openness to male circumcision - such as expressing willingness or having heard of someone who was circumcised at the clinic - appear to be important factors. However, the most common barriers to male circumcision - fear of pain and cultural or religious norms - are not affected by price or information. These findings should be considered in designing future demand generating interventions.

Our findings have important cost-implications for the efficacy of scaling up male circumcision. In particular, our findings of low demand imply fewer total infections averted and thus lower net savings from male circumcision service provision roll-out. Many sub-Saharan governments have set targets of circumcising 80 percent of their adult male population based off the cost-effectiveness estimates in Njeuhmeli et al. (2011) which were calculated using the Decision-Makers' Program Planning Tool (DMPPT) developed by USAID and UNAIDS. This model accounts for many key parameters such as demographic, epidemiological, and cost factors but does not take into account possible population-level spillovers from increased take-up. If spillovers are important for HIV incidence, cost-effectiveness estimates would underestimate the savings lost from low 
take-up and overestimate net cost-effectiveness of circumcision roll-out programs when there is lower demand. The relevant question for male circumcision roll-out is whether countries will reach the point where circumcision coverage reaches the necessary levels to incur the savings needed to justify this particular HIV prevention strategy over others.

Low demand could be particularly important if take-up is correlated to ex-ante risk or preferences. Our results suggest there may be some selection of those who are more likely to use condoms into circumcision. If men who are at lowest risk of HIV - those with the lowest marginal social benefit - are most likely to take-up circumcision, costeffectiveness estimates could greatly overestimate the benefits of scale-up. Holding behavior constant, circumcising men with the highest marginal social benefit of the surgery first or at a faster rate maximizes the overall public health benefit of circumcision scale-up. Given the current low demand, male circumcision campaigns can be made more cost-effective if they target higher risk groups of the population such as in higher prevalence areas, or among truck drivers or the military.

Theoretically, this paper fits into a growing literature in economics on pricing of in health goods. Some argue that charging small fees might be optimal for increasing the use of products if those who value the good most are those who are most likely to pay for it (Ashraf, Berry, and Shapiro, 2010; Cohen and Dupas, 2010; Kremer and Holla, 2009; Cohen et al., 2012). A positive priced good might also signal that the product is of higher quality or effectiveness (Bagwell and Riordan 1991; Riley 2001) or those who pay for a good may view the investment as a sunk cost and therefore be more likely to use it (Thaler 1980; Arkes and Blumer 1985). Despite these arguments a number of other experiments have found large responses to prices of health goods and benefits to offering products for free (Kremer and Miguel, 2007); Cohen and Dupas, 2009; Ashraf, Berry and Shapiro, 2010). In this study, we find no statistically significant difference in take-up between those offered a circumcision for free compared to those who were charged the smallest amount; however, we are limited by a lack of statistical power. Our finding of very low take-up even when the procedure was offered for free suggests large additional costs to getting circumcised. These costs may be psychological, or may be related to 
strong cultural or religious norms. In addition, in contrast to much of the existing literature estimating the willingness to pay for products offered during door-to-door campaigns, the willingness to pay for health products or services that need to be conducted at a health center may be substantially lower.

It is important to note that the results in this paper may not generalize to other SubSaharan African countries or to other service delivery models. However, providing male circumcision services in existing facilities is a common delivery model and has been suggested in many countries' rollout plans. In addition, these results are among the very first adopters and the findings may not generalize to other contexts or latter in the adoption process. The results on the determinants of take-up are identified off of a small sample of men, suggesting caution in overgeneralizing the results. Lastly, our results are not informative for predicting responses to "negative prices" or financial incentives.

The findings in this paper do provide the first rigorous estimates of the demand for medical male circumcision and shed light on some of the real challenges for scaling up circumcision coverage to meet global targets. With the goal of reducing HIV infections, scaling up medical male circumcisions has become a high priority. However, there must be joint efforts on both increasing demand particularly among high risk groups and ensuring reliable supply of quality services during scale-up. Reducing prices or providing information may be one way to reach targeted levels of male circumcision coverage, but clearly is not the only strategy needed. How to incentivize high risk adult men in endemic areas to get circumcised is an important question for future research. 


\section{References}

Albert, A. L. A. A. L. M., Akol, A., L'engle, K., Tolley, E. E., Ramirez, C. B., \& Opio, A., et al. (2011).Acceptability of male circumcision for prevention of HIV infection among men and women in Uganda. AIDS Care, Epub ahead of print.

Anglewicz, P. and Kohler, H-P. (2009) “Overestimating HIV infection: The construction and accuracy of subjective probabilities of HIV infection in rural Malawi”. AIDS Behavior. Vol 14(6): pp. 103-112.

Arkes, Hal R., and Catherine Blumer, “The Psychology of Sunk Cost,” Organizational Behavior and Human Decision Processes, 35 (1985), 124-140.

Ashraf, N., J. Berry, and J.M. Shapiro. 2010. “Can Higher Prices Stimulate Product Use? Evidence from a Field Experiment in Zambia.” American Economic Review 100(5): 2383-2413.

Auvert, B., D. Taljaard, et al. (2005). "Randomized, controlled intervention trial of male circumcision for reduction of HIV infection risk: the ANRS 1265 Trial." PLoS Med 2(11): e298.

Bailey, R. C., Muga, R., et al. (2002). “The acceptability of male circumcision to reduce HIV infections in Nyanza Province, Kenya. AIDS Care, 14(1), 27-40.

Bailey, Robert C, Stephen Moses, et al. 2007. "Male circumcision for HIV prevention in young men in Kisumu, Kenya: a randomised controlled trial”. Lancet. Volume 369, Issue 9562, 24 February 2007-2 March 2007, Pages 643-656

Bengo, Joseph Mfutso et al. (2010). Situation Analysis of Male Circumcision in Malawi, Blantyre, Malawi: University of Malawi College of Medicine.

Cassell, M. M. and D. T. Halperin, et al. (2006). "Risk compensation: the Achilles' heel of innovations in HIV prevention?" BMJ 332(7541): 605-607.

CHIPTS. (2008). “The Future Direction of Male Circumcision in HIV Prevention”. Center for HIV Identification, Prevention, and Treatment Services Conference Proceedings. 
Cohen, Jessica and Pascaline Dupas. 2010. "Free Distribution or Cost Sharing? Evidence from a Randomized Malaria Prevention Experiment.” Quarterly Journal of Economics 125(1): 1-45.

Cohen, Jessica; Pascaline Dupas and Simone G. Schaner. 2012. "Price Subsidies, Diagnostic Tests, and Targeting of Malaria Treatment: Evidence from a Randomized Controlled Trial”, NBER Working Paper 17943.

Godlonton, Susan, Alister Munthali and Rebecca Thornton. (2013). "Behavioral Response to Information? Circumcision, Information, and HIV Prevention”. University of Michigan Working Paper

Goldberg, Jessica. (2012) “Kwacha Gonna Do? Experimental Evidence about Labor Supply in Rural Malawi.” Working paper, University of Maryland.

Gray, RH, G Kigozi et al. 2007. "Male circumcision for HIV prevention in men in Rakai, Uganda: a randomised trial”, Lancet 369, pp. 657-666.

Hankins, C., S. Forsythe, and Njeuhmeli, E. (2011). "Voluntary medical male circumcision: an introduction to the cost, impact, and challenges of accelerated scaling up." PLoS Med 8(11): e1001127.

Herman-Roloff, A., Otieno, N., Agot, K., Ndinya-Achola, J. O., \& Bailey, R. C. (2011). Acceptability of medical male circumcision among uncircumcised men in Kenya one year after the launch of the national male circumcision program. PLOS ONE, 6(5), e19814.

IRIN Plus News. (2012) “MALAWI: Government finally moves on Male Circumcision”, Feb 10, 2012.Accessed at: http://www.irinnews.org/report.aspx?reportid=94832 Jung, Jaehyun. (2012). “Male Circumcision Pilot Program in Lilongwe, Malawi”. Consilience: The Journal of Sustainable Development Vol. 7, 1 (2012), pp. 103-114 Kalichman S, Eaton L, Pinkerton S, 2007 Circumcision for HIV Prevention: Failure to Fully Account for Behavioral Risk Compensation. PLoS Med 4(3): e138. doi:10.1371/journal.pmed.0040138

Kremer, Michael and Alaka Holla. 2009. "Pricing and Access: Lessons from Randomized Evaluations in Education and Health.” In What Works in Development? Thinking Big 
and Thinking Small, ed. Jessica Cohen and William Easterly, 91-119. Washington DC: Brookings Institution Press.

Kremer, Michael and Edward Miguel. 2007. "The Illusion of Sustainability.” Quarterly Journal of Economics 122(3):1007-1065.

Lawson, M., Mazengera, S. Nkhoma-Mbawa, F. et al. (2008). "Malawi Essential Health Services Campaign”, Oxfam Research Report. Oxfam International.

Lukobo, M., \& Bailey, R. C. (2007). Acceptability of male circumcision for prevention of HIV infection in Zambia. AIDS Care, 19(4), 471-477.

Mattson CL, Campbell RT, Bailey RC, Agot K, Ndinya-Achola JO, et al. (2008) Risk

Compensation Is Not Associated with Male Circumcision in Kisumu, Kenya: A Multi-

Faceted Assessment of Men Enrolled in a Randomized Controlled Trial. PLoS ONE

3(6): e2443. doi:10.1371/journal.pone.0002443

Mills, J.; N. Siegfried (October 2006). "Cautious optimism for new HIV/AIDS

prevention strategies." Lancet 368 (9543): 1236, Garenne, Michel (January 2006). "Male

Circumcision and HIV Control in Africa." PLoS Medicine 3 (1): e78).

Muula, A. S. (2007). "Male circumcision to prevent HIV transmission and acquisition: what else do we need to know?" AIDS Behavior 11(3): 357-363.

MDHS. (2010). Malawi Demographic and Health Survey 2010. Zomba, Malawi and

Calverton, MD: National Statistical Office [Malawi] and ICF Macro.

Nagelkerke, N. J., S. Moses, et al. (2007). "Modelling the public health impact of male circumcision for HIV prevention in high prevalence areas in Africa." BMC Infect Dis 7: 16 .

Namangale, Frank. (2007). “Approach Male Circumcision with Caution”. Malawi Daily Times. March 9, 2007.

Ngalande, Rebecca et al. (2006). Acceptability of Male Circumcision for Prevention of HIV Infection in Malawi. AIDS and Behavior, vol. 10(4), pp. 377-385.

Njeuhmeli, Emmanuel., S. Forsythe, et al. (2011) “Voluntary Medical Male

Circumcision: Modeling the Impact and Cost of Expanding Male Circumcision for HIV Prevention in Eastern and Southern Africa”. PLoS Medicine 8(11): e1001132. doi:10.1371/journal.pmed.1001132 
PlusNews (2010) "UGANDA: Strong turnout as male circumcision kicks off in the north”, Accessed on 24/02/2012 at:

http://www.irinnews.org/report.aspx?ReportID=91433

Stannus, H. S. and J. B. Davey (1913). "The Initiation Ceremony for Boys Among the Yao of Nysaland." The Journal of the Royal Anthropological Institute of Great Britain and Ireland 43: 119-123.

Tenthani, Raphael. (2010). “Malawi Rules Out Circumcision for AIDS Prevention”. Associated Press.

Thom, A. (2009) “South Africa: High Demand for Male Circumcision” Accessed on 24/02/201 at: http://allafrica.com/stories/200907220206.html

Thornton, R. (2008). "The Demand for and Impact of Learning HIV Status: Evidence from a Field Experiment." American Economic Review. 98(5): 1829-63.

Thornton, R.(2012). “HIV Testing, Subjective Beliefs and Economic Behavior.” Journal of Development Economics, Volume 99, Issue 2, Pages 300-313.

Westercamp, N. and R. C. Bailey (2007). "Acceptability of male circumcision for prevention of HIV/AIDS in sub-Saharan Africa: a review." AIDS Behavior 11(3): 341355.

Westercamp, M., Agot, K. E., Ndinya-Achola, J. O., \& Bailey, R. C. (2012).

“Circumcision preference among women and uncircumcised men prior to scale-up of male circumcision for HIV prevention in Kisumu, Kenya.” AIDS Care, 24(2), 157-166.

White RG, Glynn JR, et al. (2008) Male circumcision for HIV prevention in sub-Saharan Africa: who, what and when? AIDS 22: 1841-1850.

WHO. (2007). “New Data on Male Circumcision and HIV Prevention: Policy and Programme Implications WHO/UNAIDS Technical Consultation on Male Circumcision and HIV Prevention: Research Implications for Policy and Programming”, Montreux, 6 - 8 March 2007

WHO (2011), Joint United Nations Programme on HIV/AIDS (2010) Progress in male circumcision scale-up: country implementation and research update. Geneva: World 
Health Organization. Available: http://www.malecircumcision.org/document s/MC_country_June2010.pdf. Accessed 25 August 2011.

Williams BG, Lloyd-Smith JO, et al. (2006). The potential impact of male circumcision on HIV in sub-Saharan Africa. PLoS Med 3: e262. doi:10.1371/journal.pmed.0030262.

Wilson, N., W. Xiong and Mattson, C.L. (2013). “Is Sex Like Driving? Risk

Compensation Associated with Male Circumcision in Kisumu, Kenya”. Williams College Working Paper.

UNAIDS/WHO/SACEMA Expert Group on Modeling the Impact and Cost of Male Circumcision for HIV Prevention (2009). "Male Circumcision for HIV Prevention in High HIV Prevalence Settings: What Can Mathematical Modelling Contribute to Informed Decision Making?” PLoS Med 6(9): e1000109. doi:10.1371/ journal.pmed.1000109

UNAIDS, (2010). Global Report: UNAIDS Report on the global AIDS epidemic 2010. http://www.unaids.org/GlobalReport/Global_report.htm.

Zimdiaspora. (2010) “3000 men circumcised in pilot programme” Friday February $5^{\text {th }}$, 2010. Accessed on 24/02/2012 at:

http://www.zimdiaspora.com/index.php?option=com_content\&view=article

\&id=2759:3-000-men-circumcised-in-pilot-programme\&catid=38:traveltips\&Itemid=18 
Figure 1: Reasons against circumcision

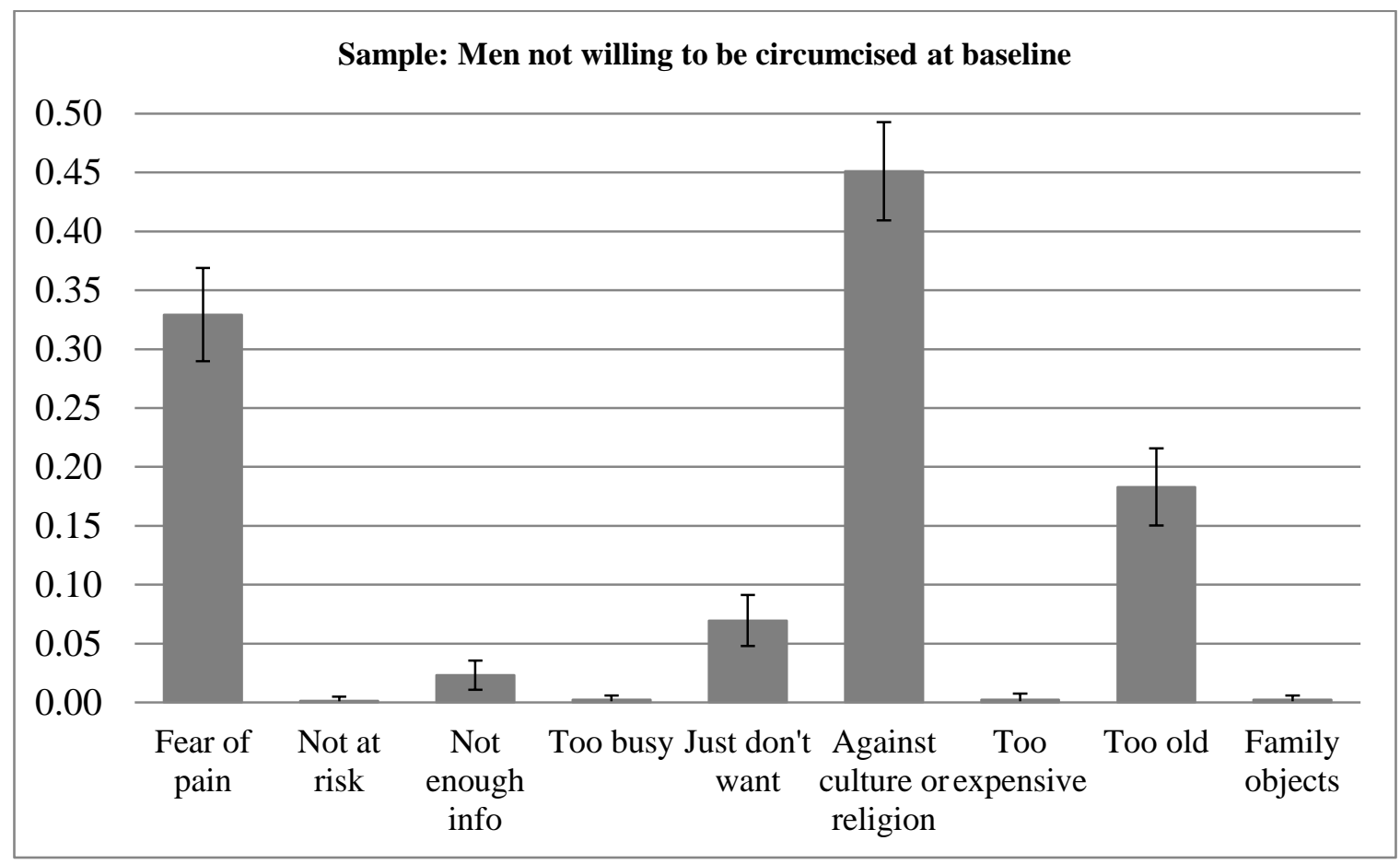

Notes: Sample includes 1634 men interviewed at baseline. Circumcision is measured by clinical records. Average rate was 2.6 percent. 
Figure 2: Medical Male Circumcision and Price of Circumcision

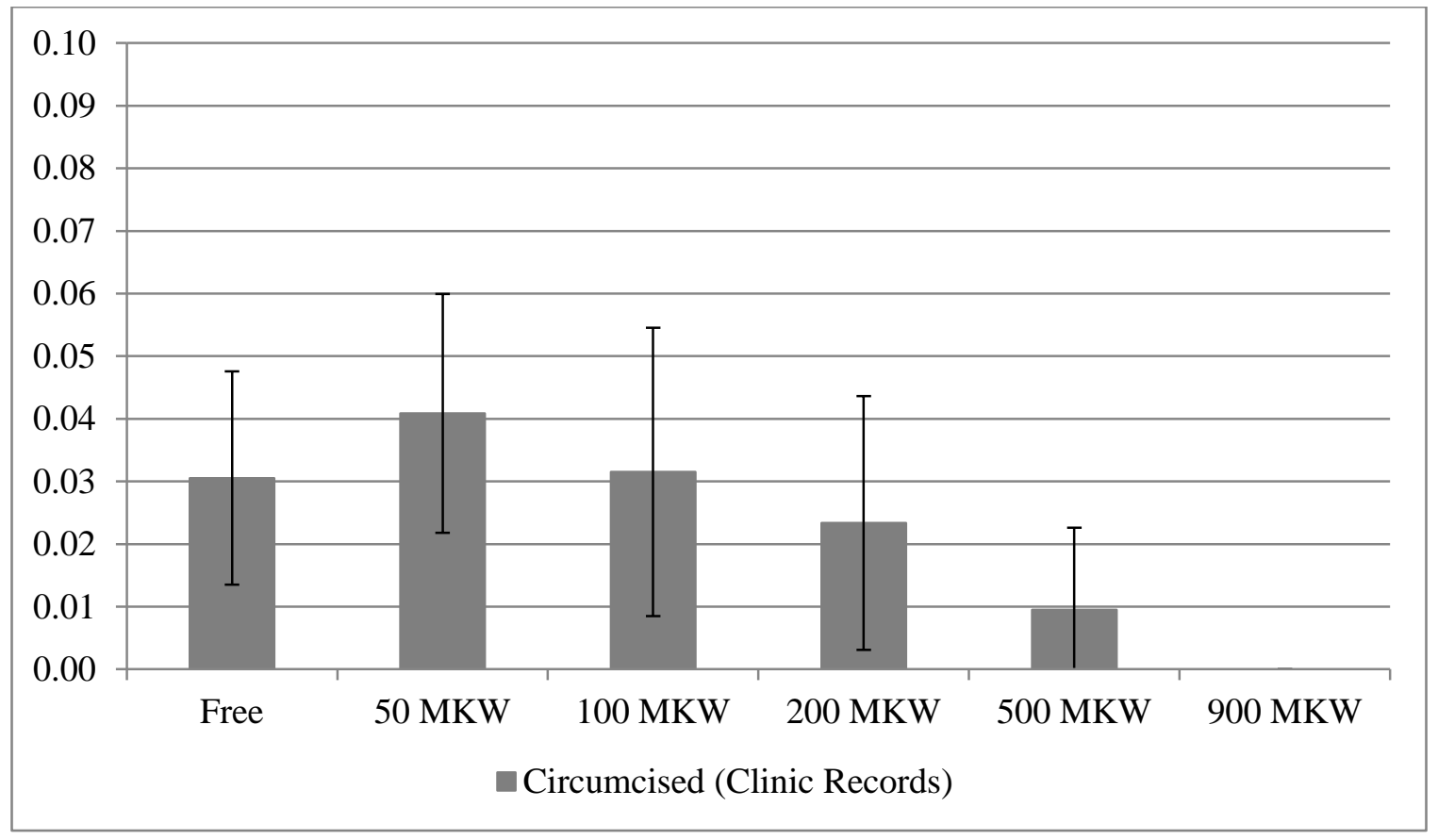

Notes: Sample includes 1634 men interviewed at baseline. Circumcision is measured by clinical records. Average rate was 2.6 percent. 
Figure 3: Medical Male Circumcision and Information

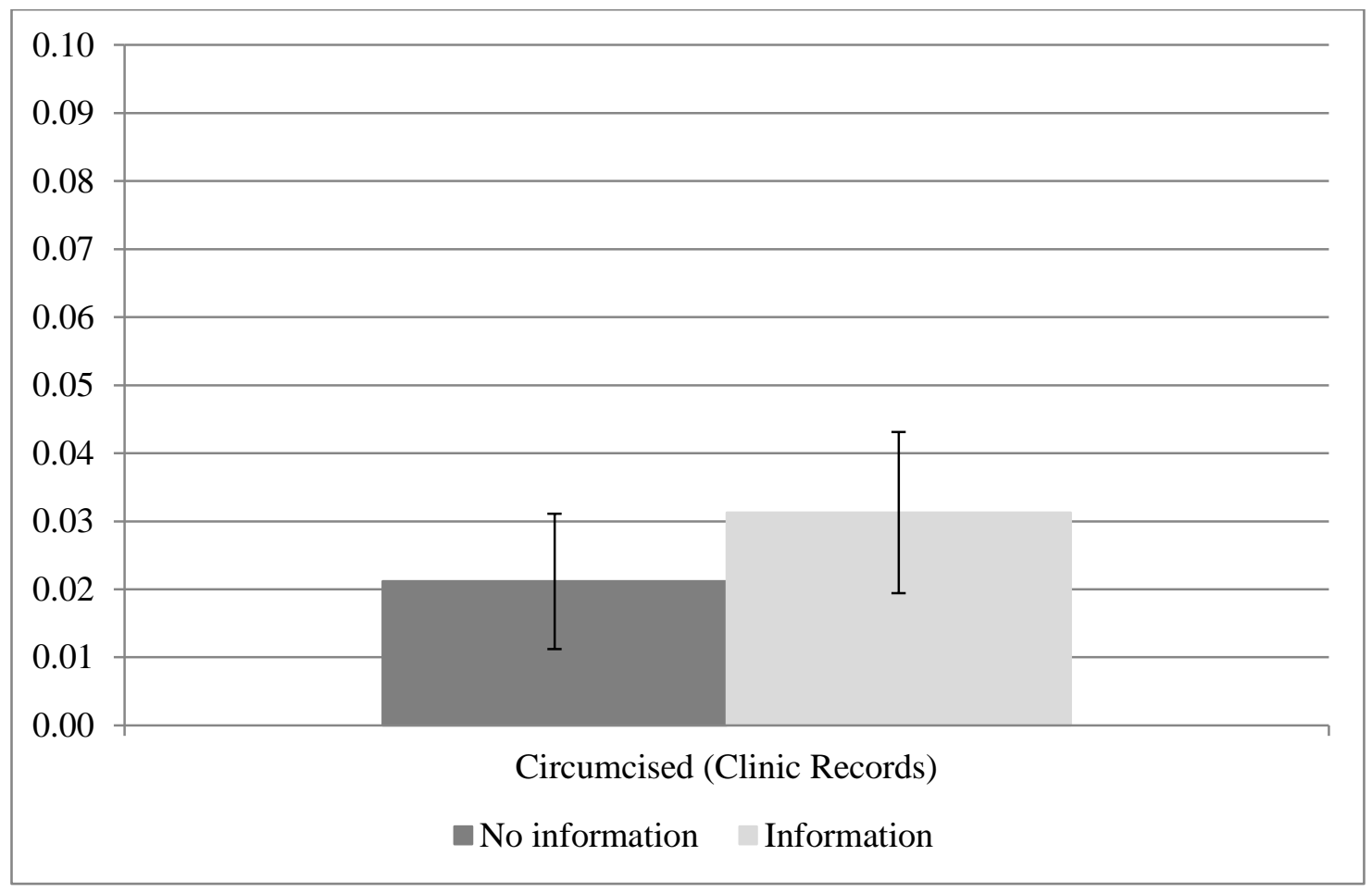

Notes: Sample includes 1634 men interviewed at baseline. Circumcision is measured by clinical records. 
Figure 4: Medical Male Circumcision, Price and Information

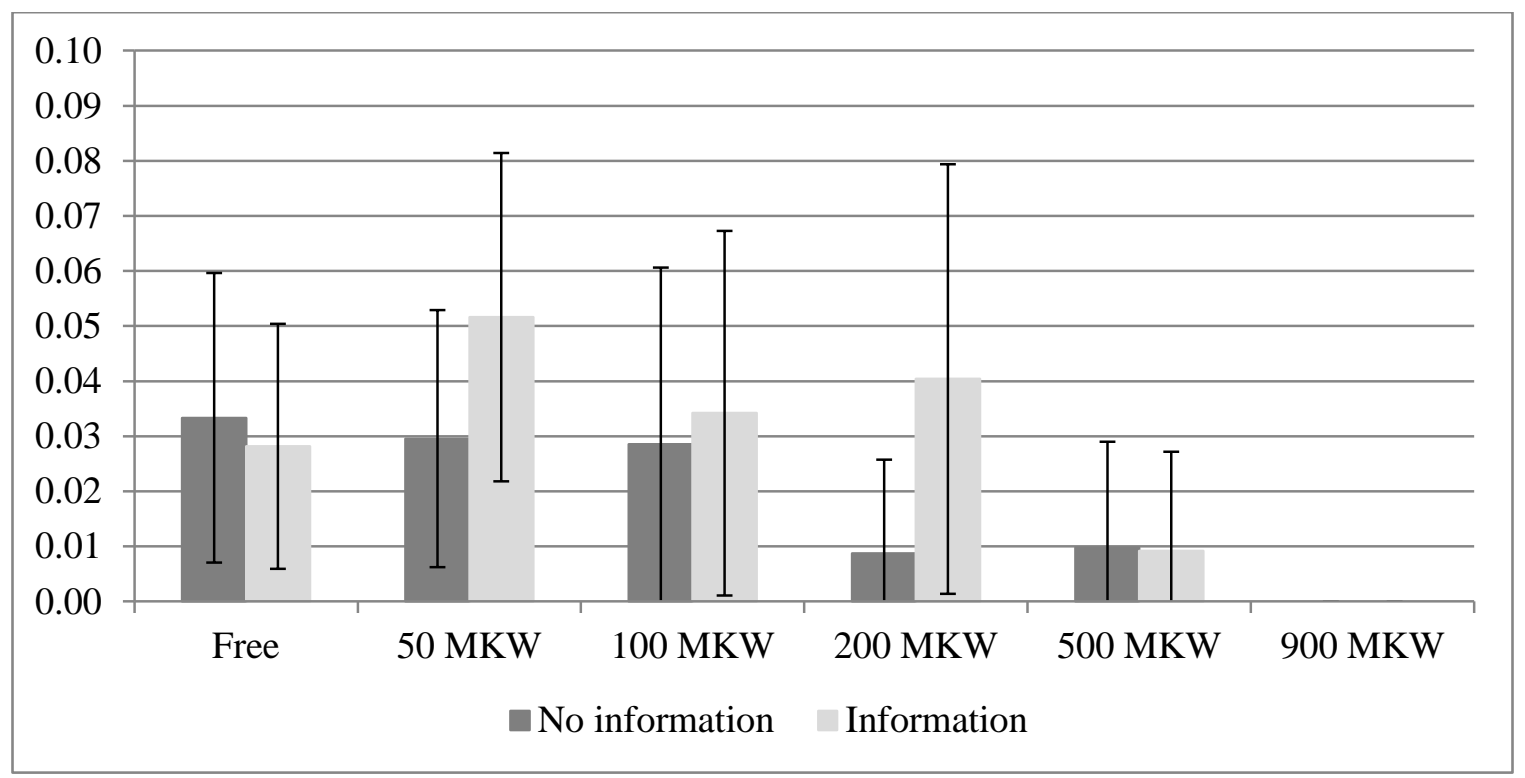

Notes: Sample includes 1634 men interviewed at baseline. Circumcision is measured by clinical records. 
Table 1: Sample Statistics - Full Sample

Age

Years of schooling

Expenditures

Circumcising tribe

Num sex acts last month

Multiple partners in past month

Abstinence last month

Condom use at last sex

Belief of high likelihood HIV

Ever had an HIV test

Willingness to circumcise

Circumcision is protective

Heard of anyone circumcised at clinic

Distance to the clinic (in km)

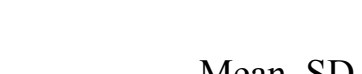

Balance

Attrition

\begin{tabular}{clcccc}
\multicolumn{2}{c}{$\begin{array}{c}\text { Mean, SD } \\
(1)\end{array}$} & $\begin{array}{c}\text { Information } \\
(2)\end{array}$ & $\begin{array}{c}\text { Prices } \\
(3)\end{array}$ & $\begin{array}{c}\text { Information } \\
(4)\end{array}$ & $\begin{array}{c}\text { Prices } \\
(5)\end{array}$ \\
\hline 26.674 & 5.787 & 0.739 & 0.777 & 0.198 & 0.250 \\
11.055 & 2.466 & 0.320 & 0.164 & 0.073 & 0.848 \\
$21,325.05$ & $27,371.47$ & 0.718 & 0.534 & 0.727 & 0.177 \\
0.171 & 0.376 & 0.717 & 0.784 & 0.199 & 0.465 \\
4.284 & 7.128 & 0.884 & 0.902 & 0.949 & 0.843 \\
0.058 & 0.234 & 0.003 & 0.037 & 0.147 & 0.931 \\
0.461 & 0.499 & 0.656 & 0.169 & 0.614 & 0.971 \\
0.395 & 0.489 & 0.040 & 0.304 & 0.418 & 0.393 \\
0.217 & 0.413 & 0.959 & 0.699 & 0.598 & 0.256 \\
0.482 & 0.500 & 0.873 & 0.771 & 0.798 & 0.044 \\
0.493 & 0.500 & 0.058 & 0.884 & 0.150 & 0.098 \\
0.488 & 0.500 & 0.207 & 0.978 & 0.338 & 0.587 \\
0.194 & 0.396 & 0.048 & 0.601 & 0.218 & 0.113 \\
0.969 & 0.442 & 0.044 & 0.316 & 0.922 & 0.169 \\
\hline
\end{tabular}

\section{Notes:}

Notes: Sample consists of 1634 men who were interviewed at baseline. Expenditures categories were: Clothes, fabric, or shoes, Medical expenses at a clinic, doctor, pharmacy, or traditional doctor, Food: maizes, meat, vegetables, eating out, transportation costs, and cell phone minutes. Median expenditures were $12,000 \mathrm{Kwacha}$. Believing circumcision is protective is generated from two questions that asked: i) "If 100 circumcised men each slept with a woman who is HIV positive last night, how many of them do you think would get HIV?"; and ii) "If 100 uncircumcised men each slept with a woman who is HIV positive last night, how many of them do you think would get HIV?"

Columns 2 and 3 present the p-values from separate regressions testing the difference in each baseline variable across the information treatment group (Column 2), or circumcision price (Column 3). Columns 4 and 5 present the p-values from separate regressions of being in the follow-up sample on each baseline variable interacted with information treatment indicator (Column 4) or an indicator of each price (Column 5). The p-values are either on the interaction of information and baseline variable, or the joint test of the interactions of each price and the baseline variable. 
Panel A: Full Sample ( $\mathrm{N}=1634)$

Clinic Data

Circumcised

Panel B: Follow-up Sample (N=1252)

Clinic Data

Circumcised

Survey Data

Any interaction with the partner clinic about circumcision

Circumcised at non-partner clinic

Circumcised at partner clinic after validity period

Circumcised at partner clinic during validity period

Total (clinic or survey)

Circumcised

Panel C: Validity Checks of Clinical Circumcisions (N=41)

Reports being circumcised at partner clinic

Reports not being circumcised

\begin{tabular}{cc}
$\begin{array}{c}\text { Number of } \\
\text { Men }\end{array}$ & $\begin{array}{c}\text { \% of Full } \\
\text { Sample }\end{array}$ \\
$(1)$ & $(2)$ \\
\hline 43 & 0.0263
\end{tabular}

\begin{tabular}{ccc}
$\begin{array}{c}\text { Number of } \\
\text { Men } \\
(1)\end{array}$ & $\begin{array}{c}\text { (2) } \\
(239\end{array}$ & $\begin{array}{c}0.7772 \\
(3)\end{array}$ \\
\hline 41 & 0.033 & 0.369 \\
326 & 0.260 & $\mathrm{~N} / \mathrm{A}$ \\
& & \\
25 & 0.020 & 0.225 \\
9 & 0.007 & 0.081 \\
36 & 0.029 & 0.324 \\
& & \\
111 & 0.089 & \\
& & $\%$ of Clinic \\
Number of & $\%$ of Follow- & Records (N=41) \\
Men & up Sample & $(3)$ \\
$(1)$ & $(2)$ & 0.854 \\
\hline 35 & 0.028 & 0.146 \\
6 & 0.005 &
\end{tabular}

\section{Notes:}

Panel A includes the full sample of men who were interviewed at the baseline. Panel B includes 1,252 men who were interviewed at both baseline and follow-up. Panel $\mathrm{C}$ includes the sample of 41 men who had clinic records and follow-up surveys. Interaction with the partner clinic includes a male circumcision, counseling, visits, or phone calls. 
Table 3: Voluntary Medical Male Circumcision Take-Up and Price

\begin{tabular}{|c|c|c|c|c|c|c|c|c|}
\hline \multirow[t]{3}{*}{ Dependent Variable: } & \multirow{2}{*}{\multicolumn{2}{|c|}{$\begin{array}{l}\text { Circumcised } \\
\qquad(\text { Clinic }) \\
\text { Full Sample }\end{array}$}} & \multirow{2}{*}{\multicolumn{2}{|c|}{$\begin{array}{l}\text { Circumcised } \\
\text { (Clinic) }\end{array}$}} & \multirow{2}{*}{\multicolumn{2}{|c|}{$\begin{array}{c}\text { Circumcised } \\
\text { (Self-Report: Valid Clinic }+ \\
\text { Non-expired Clinic }) \\
\text { Follow-up Sample }\end{array}$}} & \multirow{2}{*}{\multicolumn{2}{|c|}{$\begin{array}{c}\text { Any clinic interaction (Self- } \\
\text { Report) }\end{array}$}} \\
\hline & & & & & & & & \\
\hline & (1) & (2) & (3) & $(4)$ & $(5)$ & (6) & $(7)$ & $(8)$ \\
\hline \multirow[t]{2}{*}{ Free } & $0.031 * * *$ & $0.026 * *$ & $0.036 * * *$ & $0.030 * *$ & $0.065 * * *$ & $0.054 * * *$ & $0.108 * *$ & $0.107 * *$ \\
\hline & {$[0.012]$} & {$[0.011]$} & {$[0.013]$} & {$[0.013]$} & {$[0.018]$} & {$[0.019]$} & {$[0.050]$} & {$[0.052]$} \\
\hline \multirow[t]{2}{*}{$50 \mathrm{MKW}$} & $0.041 * * *$ & $0.038 * * *$ & $0.053 * * *$ & $0.051 * * *$ & $0.080 * * *$ & $0.066 * * *$ & $0.132 * *$ & $0.140 * *$ \\
\hline & {$[0.010]$} & {$[0.010]$} & {$[0.013]$} & {$[0.014]$} & {$[0.019]$} & {$[0.016]$} & {$[0.055]$} & {$[0.055]$} \\
\hline \multirow[t]{2}{*}{$100 \mathrm{MKW}$} & $0.032 * *$ & $0.026^{*}$ & $0.035 * *$ & 0.027 & $0.063 * * *$ & $0.050 * *$ & $0.142 * *$ & $0.142 * *$ \\
\hline & {$[0.014]$} & {$[0.013]$} & {$[0.017]$} & {$[0.017]$} & {$[0.023]$} & {$[0.022]$} & {$[0.057]$} & {$[0.058]$} \\
\hline \multirow[t]{2}{*}{$200 \mathrm{MKW}$} & $0.023 * *$ & $0.023 * *$ & $0.031 * *$ & $0.029 * *$ & $0.042 * *$ & $0.042 * *$ & $0.104 * *$ & $0.102 * *$ \\
\hline & {$[0.010]$} & {$[0.010]$} & {$[0.013]$} & {$[0.013]$} & {$[0.018]$} & {$[0.018]$} & {$[0.050]$} & {$[0.051]$} \\
\hline \multirow[t]{2}{*}{$500 \mathrm{MKW}$} & 0.009 & 0.006 & 0.012 & 0.010 & 0.029 & 0.025 & 0.086 & 0.077 \\
\hline & {$[0.007]$} & {$[0.008]$} & {$[0.009]$} & {$[0.011]$} & {$[0.018]$} & {$[0.017]$} & {$[0.063]$} & {$[0.063]$} \\
\hline Observations & 1,634 & 1,634 & 1,252 & 1,252 & 1,252 & 1,252 & 1,252 & 1,252 \\
\hline R-squared & 0.007 & 0.034 & 0.009 & 0.040 & 0.011 & 0.049 & 0.008 & 0.067 \\
\hline Incl. controls? & $\mathrm{N}$ & Y & $\mathrm{N}$ & Y & $\mathrm{N}$ & Y & $\mathrm{N}$ & $\mathrm{Y}$ \\
\hline $\begin{array}{l}\text { Ave of dep variable }(900 \\
M K W)\end{array}$ & \multicolumn{2}{|c|}{0.000} & \multicolumn{2}{|c|}{0.000} & \multicolumn{2}{|c|}{0.008} & \multicolumn{2}{|c|}{0.157} \\
\hline
\end{tabular}

Notes:

Robust standard errors clustered by block and interview date. Control variables include: age, age squared, logged total expenditures, years of schooling, whether the respondent is of a circumcising tribe, whether the respondent reported he was willing to be circumcised, if the respondent thought his risk of having HIV was high, if the respondent ever had an HIV test, the interaction of belief of high risk and having an HIV test, if the respondent had heard of anyone who circumcised at the partner clinic, if the respondent correctly believed that circumcision was associated with lower risk of HIV, distance to the clinic, number of sex acts in the last month, and indicators for whether the respondent used a condom at last sex, abstinence in the last month, and multiple concurrent partnerships. We also include an indicator of whether the respondent was allocated to the information treatment. For covariates with missing values, the median has been imputed, and a dummy included for whether or not the covariate is missing included. * significant at $10 \%$; ** significant at $5 \%$; *** significant at $1 \%$. Interaction with the partner clinic includes male circumcision, counseling, visits, or phone calls. 
Table 4: Voluntary Medical Male Circumcision Take-Up and Comprehensive Information

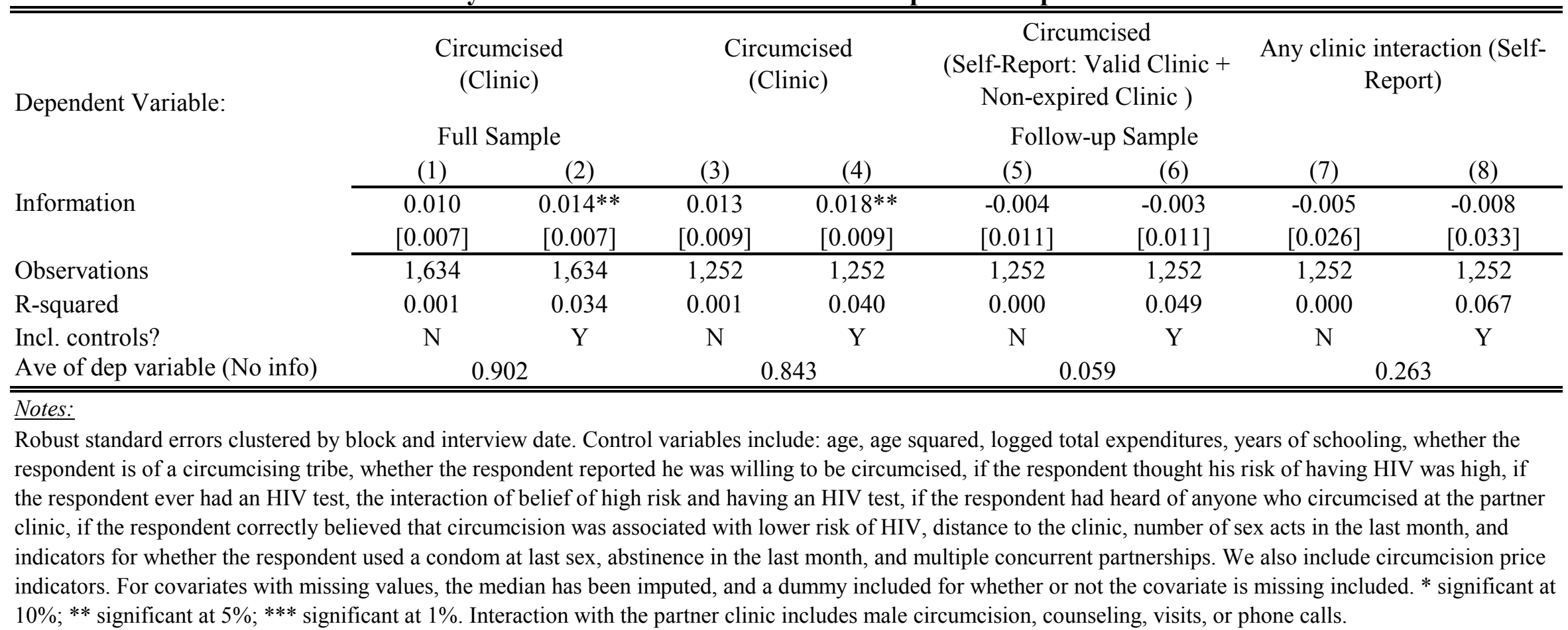


Table 5: Determinants of Take-Up

\begin{tabular}{|c|c|c|c|c|}
\hline \multirow[t]{2}{*}{ Dependent Variable: } & $\begin{array}{l}\text { Circumcised } \\
\text { (Clinic) }\end{array}$ & $\begin{array}{l}\text { Circumcised } \\
\quad \text { (Clinic) }\end{array}$ & $\begin{array}{c}\text { Circumcised } \\
\text { (Self-Report: Valid Clinic }+ \\
\text { Non-expired Clinic })\end{array}$ & $\begin{array}{l}\text { Any clinic } \\
\text { interaction (Self } \\
\text { report) }\end{array}$ \\
\hline & $\begin{array}{l}\text { Full Sample } \\
\text { (1) }\end{array}$ & $(2)$ & $\begin{array}{c}\text { Follow-up Sample } \\
\text { (3) }\end{array}$ & $(4)$ \\
\hline Age & $\begin{array}{c}-0.002 \\
{[0.002]}\end{array}$ & $\begin{array}{c}-0.002 \\
{[0.003]}\end{array}$ & $\begin{array}{c}-0.000 \\
{[0.003]}\end{array}$ & $\begin{array}{c}-0.016^{* *} \\
{[0.007]}\end{array}$ \\
\hline Age squared & $\begin{array}{c}0.000 \\
{[0.000]}\end{array}$ & $\begin{array}{c}0.000 \\
{[0.000]}\end{array}$ & $\begin{array}{l}-0.000 \\
{[0.000]}\end{array}$ & $\begin{array}{c}0.000^{* * *} \\
{[0.000]}\end{array}$ \\
\hline Years of education & $\begin{array}{c}-0.001 \\
{[0.002]}\end{array}$ & $\begin{array}{c}-0.001 \\
{[0.003]}\end{array}$ & $\begin{array}{c}-0.000 \\
{[0.003]}\end{array}$ & $\begin{array}{l}-0.004 \\
{[0.005]}\end{array}$ \\
\hline Log expenditures & $\begin{array}{c}0.001 \\
{[0.003]}\end{array}$ & $\begin{array}{c}-0.000 \\
{[0.005]}\end{array}$ & $\begin{array}{c}0.003 \\
{[0.007]}\end{array}$ & $\begin{array}{c}0.014 \\
{[0.011]}\end{array}$ \\
\hline Circumcising tribe & $\begin{array}{c}0.012 \\
{[0.012]}\end{array}$ & $\begin{array}{c}0.018 \\
{[0.016]}\end{array}$ & $\begin{array}{c}0.019 \\
{[0.018]}\end{array}$ & $\begin{array}{c}0.010 \\
{[0.028]}\end{array}$ \\
\hline Distance from clinic & $\begin{array}{l}-0.018^{*} \\
{[0.010]}\end{array}$ & $\begin{array}{l}-0.022^{*} \\
{[0.013]}\end{array}$ & $\begin{array}{c}-0.006 \\
{[0.011]}\end{array}$ & $\begin{array}{c}0.000 \\
{[0.050]}\end{array}$ \\
\hline \# sex acts in last month & $\begin{array}{c}-0.001 \\
{[0.001]}\end{array}$ & $\begin{array}{c}-0.001 \\
{[0.001]}\end{array}$ & $\begin{array}{l}-0.000 \\
{[0.001]}\end{array}$ & $\begin{array}{c}0.000 \\
{[0.002]}\end{array}$ \\
\hline Multiple partners indicator & $\begin{array}{c}0.032 \\
{[0.025]}\end{array}$ & $\begin{array}{c}0.034 \\
{[0.031]}\end{array}$ & $\begin{array}{c}0.024 \\
{[0.044]}\end{array}$ & $\begin{array}{c}-0.040 \\
{[0.060]}\end{array}$ \\
\hline Abstained in last month & $\begin{array}{c}-0.011 \\
{[0.012]}\end{array}$ & $\begin{array}{l}-0.008 \\
{[0.016]}\end{array}$ & $\begin{array}{c}0.011 \\
{[0.017]}\end{array}$ & $\begin{array}{c}0.023 \\
{[0.037]}\end{array}$ \\
\hline Used condom at last sex & $\begin{array}{c}0.007 \\
{[0.008]}\end{array}$ & $\begin{array}{c}0.011 \\
{[0.010]}\end{array}$ & $\begin{array}{c}0.051 * * * \\
{[0.014]}\end{array}$ & $\begin{array}{c}0.031 \\
{[0.026]}\end{array}$ \\
\hline High likelihood HIV+ now & $\begin{array}{c}-0.007 \\
{[0.009]}\end{array}$ & $\begin{array}{c}-0.013 \\
{[0.012]}\end{array}$ & $\begin{array}{c}0.005 \\
{[0.020]}\end{array}$ & $\begin{array}{c}0.001 \\
{[0.045]}\end{array}$ \\
\hline Had HIV test & $\begin{array}{c}-0.004 \\
{[0.009]}\end{array}$ & $\begin{array}{c}-0.003 \\
{[0.013]}\end{array}$ & $\begin{array}{c}0.017 \\
{[0.016]}\end{array}$ & $\begin{array}{c}0.083 * * * \\
{[0.022]}\end{array}$ \\
\hline High likelihood $*$ HIV test & $\begin{array}{c}0.017 \\
{[0.020]}\end{array}$ & $\begin{array}{c}0.002 \\
{[0.019]}\end{array}$ & $\begin{array}{c}-0.040 \\
{[0.028]}\end{array}$ & $\begin{array}{c}-0.089 \\
{[0.062]}\end{array}$ \\
\hline Willingness to circumcise & $\begin{array}{c}0.026 * * * \\
{[0.009]}\end{array}$ & $\begin{array}{l}0.031 * * \\
{[0.012]}\end{array}$ & $\begin{array}{l}0.034 * * \\
{[0.015]}\end{array}$ & $\begin{array}{c}0.087 * * * \\
{[0.030]}\end{array}$ \\
\hline Correct beliefs about MC & $\begin{array}{c}0.001 \\
{[0.009]}\end{array}$ & $\begin{array}{c}0.001 \\
{[0.012]}\end{array}$ & $\begin{array}{c}0.020 \\
{[0.013]}\end{array}$ & $\begin{array}{c}-0.008 \\
{[0.025]}\end{array}$ \\
\hline Heard of MC at clinic & $\begin{array}{l}0.021^{*} \\
{[0.011]}\end{array}$ & $\begin{array}{l}0.023 * \\
{[0.013]}\end{array}$ & $\begin{array}{l}0.032 * \\
{[0.019]}\end{array}$ & $\begin{array}{c}0.163 * * * \\
{[0.032]} \\
\end{array}$ \\
\hline Observations & 1,634 & 1,252 & 1,252 & 1,252 \\
\hline R-squared & 0.033 & 0.039 & 0.048 & 0.067 \\
\hline Incl. price and information indicators? & $\mathrm{Y}$ & $\mathrm{Y}$ & $\mathrm{Y}$ & $\mathrm{Y}$ \\
\hline
\end{tabular}

Notes:

Robust standard errors clustered by block and interview date. Also includes circumcision price indicators and an information treatment indicator. For covariates with missing values, the median has been imputed, and a dummy included for whether or not the covariate is missing included. * significant at $10 \%$; ** significant at $5 \%$; *** significant at $1 \%$. Interaction with the partner clinic includes male circumcision, counseling, visits, or phone calls. 
Table 6: Attitudes towards Circumcision

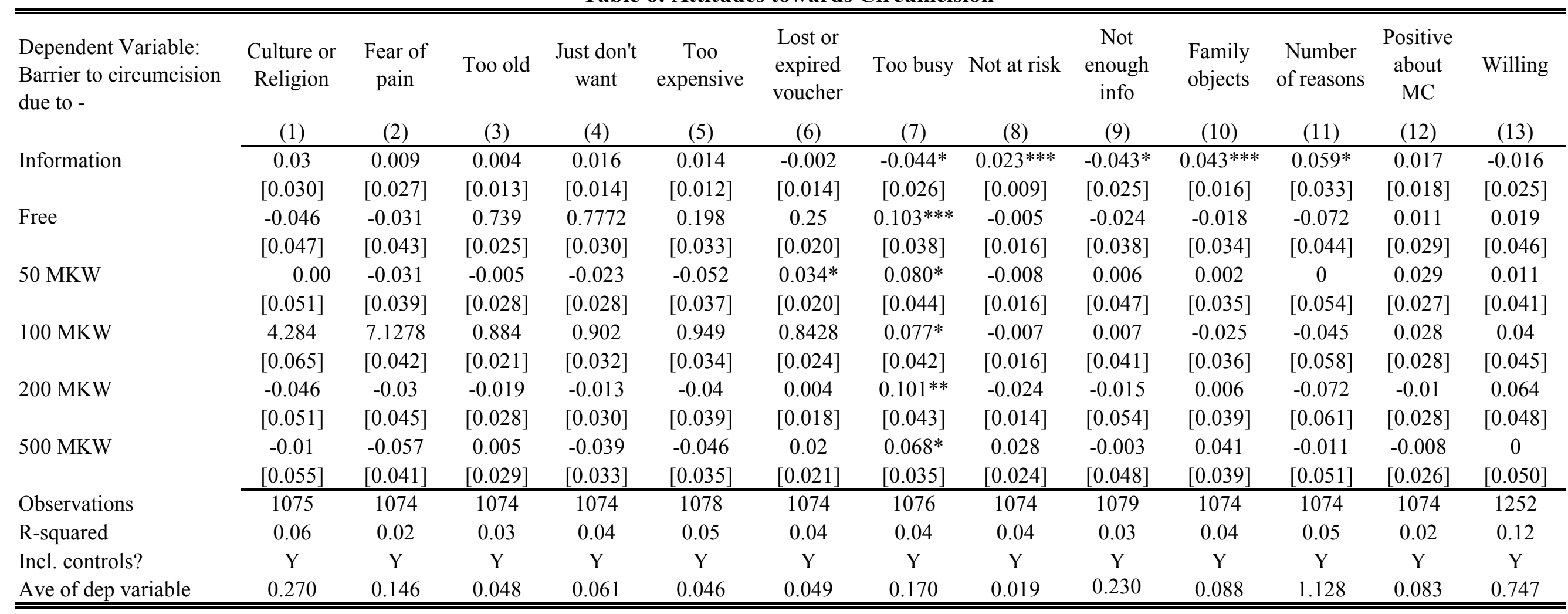

Notes:

Robust standard errors clustered by block. Control variables include: age, age squared, logged total expenditures, years of schooling, whether the respondent is of a circumcising tribe, whether the respondent reported he was willing to be circumcised, if the respondent thought his risk of having HIV was high, if the respondent ever had an HIV test, the interaction of belief of high risk and having an HIV test, if the respondent had heard of anyone who circumcised at the partner clinic, if the respondent correctly believed that circumcision was associated with lower risk of HIV, distance to the clinic, and indicators of being low risk and high risk. We also include circumcision price indicators and an information treatment indicator. For covariates with missing values, the median has been imputed, and a dummy included for whether or not the covariate is missing included. * significant at $10 \%$; ** significant at $5 \%$; *** significant at $1 \%$. Interaction with the partner clinic includes male circumcision, counseling, visits, or phone calls. 
Appendix Table A: Effects of Comprehensive Information on Circumcision Beliefs

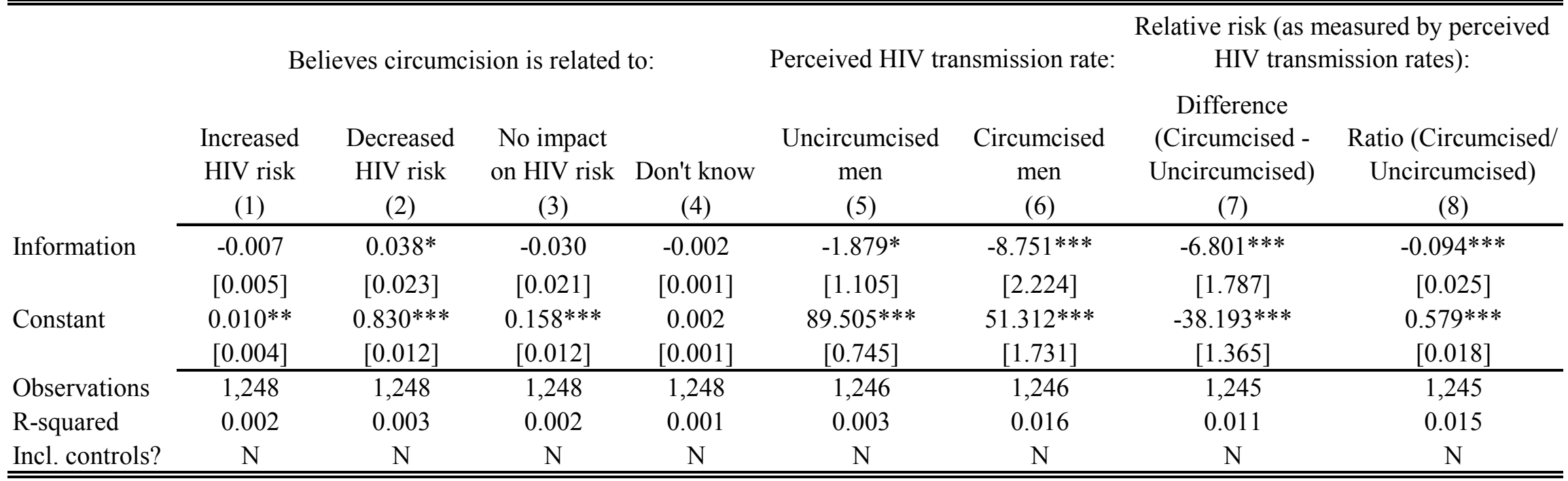

Notes:

Follow-up sample. Robust standard errors clustered by block and interview date. No baseline controls included.

* significant at $10 \%$; ** significant at 5\%; *** significant at $1 \%$ 